Journal of Social Sciences 6 (2): 256-264, 2010

ISSN 1549-3652

(C) 2010 Science Publications

\title{
The Social-Technical View of Knowledge Management in Services Industries
}

\author{
Choong Kwai Fatt and Edward Wong Sek Khin \\ Department of Accounting, Faculty of Business and Accountancy, \\ University of Malaya, Kuala Lumpur, Malaysia
}

\begin{abstract}
Problem statement: This study investigated the social-technical view of knowledge management that supported a close social and technology relationship on automotive industry in Australia. It also examined the impacts of legacy EDI groupware technology as a mean to support knowledge management in providing value creation for an automotive company. The industry viewed legacy EDI groupware as an agent in converting tacit knowledge to explicit knowledge. Approach: It was a descriptive study. In this study, an undertaking explored the implementation of this groupware application, its organisational impact, success factors and success indicators and this using the framework and analysis of legacy EDI groupware, which incorporated the objectives, strategies, success indicators and success factors. The study presented the finding of a case study of an automotive company, who contracted an external website design consultant to implement legacy EDI groupware system on their sites. The report explored the website design consultant company in order to gain an alternate perspective of topics and issues raised by the study. Results: In this study, legacy EDI groupware technology had successfully offered infrastructure to the automotive industry, which supported the acquisition of knowledge and enhanced the environment that supported the creation and management of knowledge artifacts. Conclusion: The choice and use of the legacy EDI groupware project as a means of supporting knowledge management in providing value creation for automotive industry, was because of the belief that this technology was able to provide a strategy for managing and exploiting knowledge. This project also served to help automotive industry in understanding its knowledge asset, i.e., the value of its knowledge and in assessing that the successful application of its knowledge.
\end{abstract}

Key words: Technology reform, knowledge management, value chain, supply chain

\section{INTRODUCTION}

In an article by Offsey (1997), this author asserts that it is increasingly important for organizations to identify the need to develop better techniques to manage their knowledge assets. In another articles by Newman (1997) and Nonaka (2006), these authors states that the recognition of knowledge sharing across departments, functions, or geographical locations is a core organizational competence for most organizations. As a result, groupware application technology is a tool for providing solutions to organizational competence because it allows information sharing and collaboration across departments and functions.

The following section explores why knowledge is a factor of major importance and an important indicator of the success for the Organization. Knowledge management is an extension of information systems management where the Organization gains benefits from a more effective use of its knowledge. Therefore, a view of knowledge management may is:
"Knowledge management refers as a tool by which the Organization's core competencies can be focused and developed"

Hence, this provides knowledge management with a strategic focus (Remenyi, 1999; 2004). In another article, Bernard (1996) argues that, the adoption of Intranet technology particularly groupware application also facilitates Organization-wide knowledge management. The definition of organization-wide knowledge management is:

"Organization-wide knowledge management involves the broad processes of locating, transferring and more efficiently using of the information and expertise within an enterprise" Bernard (1996)

As a result, knowledge management is concerned with decision support systems, data warehousing and

Corresponding Author: Edward Wong Sek Khin, Department of Accounting, Faculty of Business and Accountancy, University of Malaya, Kuala Lumpur, Malaysia 


\section{J. Social Sci., 6 (2): 256-264, 2010}

data mining. Therefore, knowledge management is closely associated with Intranet applications, particularly groupware applications.

Another reason why groupware applications are applications that can facilitate Organization-wide knowledge management, are that they are able to provide people with an unprecedented global many-tomany medium that allows these people to exchange information. According to Hauben and Hauben (1997), individuals around the world are now able to broadcast their isolated opinions and gain feedback from a diversified population Hauben and Hauben (1997). He also suggests the view that knowledge management is an extension of information systems management, which utilizes the exchange of business information through an IT network. This entails the exchange of information electronically between separate organizations, or between an Organization and its customer, business-to-business or business-to-customer. Such a network of exchanging information is crucial to support successful business partnerships.

However, in order to achieve knowledge superiority, an Organization must first understand its knowledge asset, i.e., the value of its knowledge, the application of that knowledge and the true cost of its IT operations (Wong, 2003; 2004). This means the Organization needs to establish a proper knowledge management project that provides a strategy for managing and exploiting such knowledge. With this in mind, the chosen legacy EDI groupware technology is an appropriate knowledge management tool, which allows inter-and intra-organizational exchange of codified information in a structured machine accessible form.

This study seeks to answer the following research questions:

- To what extent can the adoption of a knowledge management project, which involves legacy EDI groupware, serve as a mean to support knowledge management in providing value creation to the Organization?

- If so, how and why does the adoption of legacy EDI groupware KM project act as a vehicle to support knowledge management in providing value creation to the Organization? This involves the success factors, the success indicators, the strategies and the objectives of the KM projects

Below, we review the literature and discuss the research method used to examine the adoption and integration process of a legacy EDI groupware knowledge management project for an automotive company. Following this, the descriptions of the sampling design, selection of measurement scales and data analysis techniques, followed by a presentation and discussion of the results, the limitations of study and the implications for practitioners and future research.

Literature review: Having identified knowledge as a major issue and indicator of the success of an Organization, the study introduced the importance on groupware application with knowledge transformation and creating knowledge:

"Knowledge management is concerned with recognizing and managing all the organization's intellectual assets (which include knowledge, information and data) to meet business objectives" (The IMPACT Programme, 1998)

According to The IMPACT Programme (1998) report's:

"In knowledge management, the transformation of knowledge includes (1) assisting decision making, creativity and administration; (2) fulfilling statutory requirements; (3) informing, persuading or educating stakeholders; (4) giving competitive edge; (5) yielding profits, from sale or some other form of direct commercial exploitation; (6) underpinning pleasure, satisfaction or comfort-of-mind and (7) enhancing personal power" (The IMPACT Programme, 1998)

The following example shows that associated with knowledge transformation and sharing, these may be relevant to knowledge management:

"TAB racing Australia operates in a volatile betting market where the amount of money staked is not always reflected in the odds being offered. Tacit knowledge (unwritten rules) is applied to make judgments as to whether a financial exposure exits or not. This 'nose' for the business includes aspects of 'Know-how', 'know-what' and 'know-who', but the 'Knowwho' (trainers, jockeys-horse) frequently influences the close-call decisions" (The IMPACT Programme, 1998)

Authoritative authors Nonaka and Takeuchi (1995) state that:

"Knowledge management is creating knowledge and is also a process of providing 


\section{J. Social Sci., 6 (2): 256-264, 2010}

objective information by tapping the tacit, which are highly subjective insights, intuitions and hunches of individual for meeting the business objectives. Knowledge creation is also a spiraling process of interaction between tacit and explicit knowledge. Therefore, the interaction between these kinds of knowledge leads to the creation of new knowledge" (Nonaka and Takeuchi, 1995)

Table 1 illustrates how the operations of knowledge sharing and transformation relate to formulated and tacit knowledge, involving the sharing of each and the processes of the transformation of either into the other.

According to Ciborra and Patriotta (1996), the reason for the adoption of legacy EDI groupware technology in enabling the practice of knowledge management within organizations is as follows:

- Groupware application has recursive and interactive relationship between user groups, technologies and the structural properties of the Organization

- The process of codified forms of knowledge (turning tacit into explicit knowledge) will be called on, in the development of hardware and software during its designing stage. This means that knowledge is extracted from the person who developed it and stored in electronic repositories, easily accessible by anyone in the Organization" (Ciborra and Patriotta, 1996)

Another aspect as to why information technology (legacy EDI groupware) has strong interaction with organizational functionality and practice is in the social-technical theory advanced by Pan and Scarbrough (1999). According to these authors, there are three different levels of functionality and practice as outlined below:

- Infrastructure refers to the hardware/software, which enables the physical and communication contact between network members

- Infostructure refer to the formal rules that govern the exchange between the actors on the networks providing a set of cognitive resources (metaphors, common language) whereby people make sense of the events on the network

- Infoculture refer to the stock of background knowledge, which actors take for granted and which is embedded in the social relations surrounding work group processes" (Pan and Scarbrough, 1999)
Table 1:Knowledge transformation and sharing (Nonaka and Takeuchi, 1995)

\begin{tabular}{|c|c|c|}
\hline ransformation & To tacit & To formulated \\
\hline From tacit & $\begin{array}{l}\text { Share: Personal } \\
\text { interaction (social } \\
\text { processes, training) }\end{array}$ & $\begin{array}{l}\text { Transform: Formalization } \\
\text { (documentation, } \\
\text { electronic memory) }\end{array}$ \\
\hline $\begin{array}{l}\text { From } \\
\text { formulated }\end{array}$ & $\begin{array}{l}\text { Transform: } \\
\text { Internalization }\end{array}$ & $\begin{array}{l}\text { Share: Integration } \\
\text { (practicing, learning) }\end{array}$ \\
\hline
\end{tabular}

Pan and Scarbrough (1999) proposed that their findings concerning the social-technical view of knowledge management supports a close social and technology relationship. They suggest that technology is the driving factors for top management to be proactive and supportive particularly on their business performance and competitiveness.

In summary, based on the above empirical study by Ciborra and Patriotta (1996) and Pan and Scarbrough (1999), established a conclusion that the adoption of information technology including legacy EDI groupware merges closely with organizational issues.

The discussion of the framework for analyzing a knowledge management project that involved legacy EDI groupware also supports previous empirical research. The framework for the knowledge management project referred to above incorporates four stages: The objectives, the strategies, the success indicators and the success factors (Moody and Shanks, 1999).

First stage, the objectives of knowledge management project: Objectives define what a knowledge management project is trying to achieve.

According to Davenport et al. (1998), knowledge management projects can provide four types of objectives that allow Organization to achieve knowledge superiority. They are as follows:

- Creating knowledge repositories; groupware focuses on creating structured repositories to store explicit knowledge

- Improving knowledge access; groupware focuses on providing access to tacit knowledge and facilitating its transfer between the individuals

- Enhancing the knowledge environment; groupware focuses on the establishing an environment conductive to knowledge creation, transfer and use

- Managing knowledge as an asset; groupware involves in measuring the value of the knowledge assets" (Moody and Shanks, 1999)

Second stage, the strategies of knowledge management: Strategies that define the methods for achieving the objectives. 
According to Hansen et al. (1999), there are two broad types of strategy for implementing knowledge management (Moody and Shanks, 1999). They are as follows:

- Codification strategy: Codification is about turning tacit knowledge into explicit knowledge

- Personalization strategy: Personalization focuses on tacit knowledge and involves the sharing of knowledge directly between people" (Moody and Shanks, 1999)

Hansen et al. (1999) found that:

"The implementation of knowledge management in all companies use elements drawn from each strategy, either focus on one type or focus on both together. Moreover, the choice of strategy was dependent on the competitive strategy of the Organization" (Moody and Shanks, 1999)

Third stage, the success indicators for knowledge management project: Success indicators measure the effectiveness of a knowledge management project, which includes the dependent variables or the outcome measures.

According to Davenport et al. (1998), they identified four success indicators for knowledge management projects (Moody and Shanks, 1999). These are as follows:

- Growth in resources attached to the project. This refers to the increases in number of people or the size of the budget assigned to the project over its lifetime

- Growth in knowledge content and usage. This is measured by increase in the volume of knowledge stored in repositories

- Organizational initiative. This means that if the projects are the initiatives of one or two individuals they are less likely to succeed than projects that originate in Organization-wide initiatives

- Financial returns. This refers to the financial return either for the project itself or for the Organization as a whole" (Moody and Shanks, 1999)

Stage four, the success factors for knowledge management projects: Success factors define the conditions that lead to success in knowledge management projects. According to Davenport et al. (1998) and De Long and Fahey (2000), there are eight types of success factor for implementing knowledge management project (Davenport et al., 1998; Moody and Shanks, 1999; Ahmad et al., 2009). They are as follows:

- The link to economic performance. This involves money saved or earned

- Technical and organizational infrastructure. This refers to the level of involvement through technology and organizational infrastructure for the success of knowledge management project

- Flexible knowledge structure: Finding the right balance of knowledge repositories to a project

- Knowledge-friendly culture: Finding the aspects of a knowledge friendly culture

- Clear purpose and language: Clearly defined communication and objectives are important for success

- Change in motivational practices: Incentives and rewards are important to motivate people

- Multiple channels for knowledge transfer. This means providing opportunities for face to face contact as well as electronic forms of communication

- Senior management support. This implies providing funding and other resources for the success of the Organization" (Moody and Shanks, 1999)

In summary, the literature review above has attempted to provide an overview of the empirical studies by Moody and Shanks (1999) pertaining to knowledge management projects. It explored the success factors, the success indicators, the strategies and the objectives. It was then synthesized into an analysis framework and used as the basis for analysis of the case study data.

Furthermore, the exploration of the research method used to examine the role of knowledge management in the adoption and integration process of legacy EDI groupware KM project for an automotive company will be discussed. It is proposed that the analysis framework (Moody and Shanks, 1999) shown in Fig. 1, which incorporates the objectives, success indicators and success factors of Davenport et al. (1998) and the knowledge management strategies identified by Hansen et al. (1999) will be applied to this study.

\section{MATERIALS AND METHODS}

The basis of the research methodology is using an explorative case study approach. The key players identified were from the iNature Online Consultant Co and 
interviews of these individuals are part of this research (the Technical Supervisor and the Operations Director). The interviews were semi-structured and later transcribed. Each interview took about $2 \mathrm{~h}$ to complete and focused on the objectives of the particular groupware project with which the individuals were involved, the networks and research that was shaping the diffusion, design and implementation processes.

The case study also explored the relationship between legacy EDI groupware application, its organizational impact, success factors and success indicators. In addition, included is the use of informal conversations and documentary evidence in order to obtain rich process descriptions of the study.

According to Yin (1994), it is important to ensure adequate rigor in research design when utilizing case research. Therefore, the anticipation is that the analysis framework (Moody and Shanks, 1999) shown in Fig. 1, will be used as the bases for analysis of the case study data.

Background information of pilot organization: Organization A is a family owned automotive group.

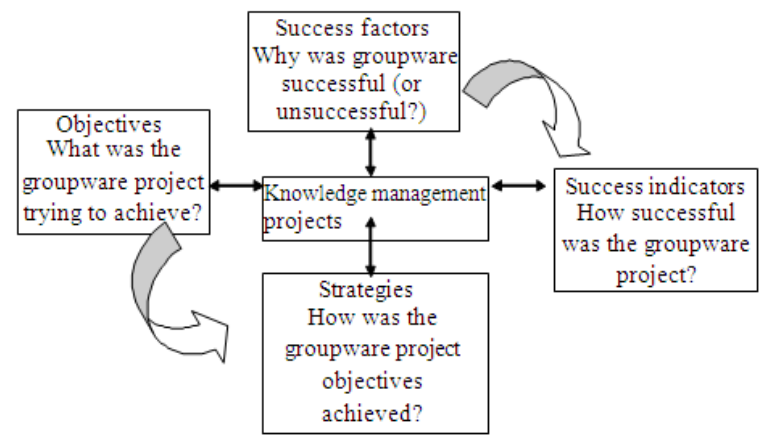

Fig. 1: Analysis framework (Moody and Shanks, 1999)
The company was to offer Western Australia car buyers an innovative option to serving vehicle needs and has been in business since the mid 1980's. Employing over 100 staff, the annual turnover is Aus $\$ 130$ million. Organization A has several Mitsubishi and Hyundai new and used vehicle franchises and five tailored used vehicle outlets, which stretches across the Perth metropolitan areas. Organization A has also 6 modern full equipped "Formula One Autocare Centers", (3 North of the river and 3 south of the river), which provide comprehensive car servicing and repairs, spare parts and accessories.

Organization A's website was designed and implemented by an external consultant (iNature Online Consultant Co) and went "live" in July 2007. A "legacy EDI" web based groupware application developed by iNature Online Consultant Co. and implemented in the Organization, which allows, management to apply to cover the implications of Intranet with its staff, suppliers and customers.

\section{RESULTS}

An analysis framework (Moody and Shanks, 1999) shown in Fig. 1, will be used as the bases for analysis of the case study data.

In this study, the respondents (the Technical Supervisor and the Operation Director from iNature Online Consultants) were invited to answer and indicate from a list of activities in the matrix on behalf for Organization A.

Stage one; objectives (Table 2): What was the groupware application project trying to achieve?

Table 2: Relationship of objectives of KM project and legacy EDI groupware matrix: Moody and Shanks (1999)

\begin{tabular}{llll}
\hline Objectives KM project & Operations staff & Existing customers & Marketing staff \\
\hline Create knowledge repositories & $\begin{array}{l}\text { Provide 24 h accessibility/ } \\
\text { accurate information provided }\end{array}$ & $\begin{array}{l}\text { Provide quick response } \\
\text { on request/queries }\end{array}$ & $\begin{array}{l}\text { Information easily accessible to } \\
\text { public }\end{array}$ \\
Improve knowledge access & $\begin{array}{l}\text { Facilitate transfer of tacit } \\
\text { knowledge between individual }\end{array}$ & Increase in satisfaction & $\begin{array}{l}\text { Facilitate transfer of tacit knowledge } \\
\text { between individual } \\
\text { Manage knowledge as an asset }\end{array}$ \\
$\begin{array}{l}\text { Moderate } \\
\text { Enhance knowledge environment }\end{array}$ & $\begin{array}{l}\text { Improve conducive environment } \\
\text { for sharing knowledge }\end{array}$ & $\begin{array}{l}\text { Increase in satisfaction } \\
\text { Moderate }\end{array}$ & $\begin{array}{l}\text { Improve conducive environment for } \\
\text { sharing knowledge }\end{array}$ \\
\hline
\end{tabular}

Table 3: Relationship of strategies of KM project and legacy EDI groupware matrix: Moody and Shanks (1999)

\begin{tabular}{llll}
\hline Strategies for the KM project & $\begin{array}{l}\text { Functionality data bases, e.g., } \\
\text { operational and administration }\end{array}$ & $\begin{array}{l}\text { External network, e.g., supplier } \\
\text { and customer focus }\end{array}$ & Listservers e.g., end-users \\
\hline Codification strategies & $\begin{array}{l}\text { Not codifying because providing } \\
\text { access to already codified knowledge }\end{array}$ & $\begin{array}{l}\text { Not codifying because providing } \\
\text { access to already codified knowledge }\end{array}$ & Not ascendable \\
Personalization strategies & Not ascendable & & $\begin{array}{l}\text { Involves exchange of ideas } \\
\text { and experiences between } \\
\text { individual end-users }\end{array}$ \\
\hline
\end{tabular}




\section{J. Social Sci., 6 (2): 256-264, 2010}

Table 4: Relationship of success indicators of KM project and legacy EDI groupware matrix: Moody and Shanks (1999)

\begin{tabular}{llll}
\hline With respect to Organization A: & Pre- adoption of groupware & Post- adoption of groupware & One years from post- adoption of groupware \\
\hline $\begin{array}{l}\text { Growth in resources attached to } \\
\text { the project }\end{array}$ & Low & Improved & High \\
$\begin{array}{l}\text { Growth in knowledge content } \\
\text { and usage }\end{array}$ & No online discussion & Increase online discussion & $\begin{array}{l}\text { Exponential increase online discussion/ } \\
\text { request/business improved }\end{array}$ \\
$\begin{array}{l}\text { Organizational initiative } \\
\text { Financial return }\end{array}$ & $\begin{array}{l}\text { Not appealing } \\
\text { Stagnant }\end{array}$ & $\begin{array}{l}\text { Satisfaction } \\
\text { Indications of cost reduction }\end{array}$ & $\begin{array}{l}\text { Increasingly Appealing/ satisfaction } \\
\text { Business improved/profit increased }\end{array}$ \\
\hline
\end{tabular}

Table 5: Relationship of success factors of KM project and legacy EDI groupware matrix: Moody and Shanks (1999)

\begin{tabular}{|c|c|c|c|}
\hline With respect to organization A: & $\begin{array}{l}\text { Pre-adoption of legacy } \\
\text { EDI groupware }\end{array}$ & $\begin{array}{l}\text { Post- adoption of legacy } \\
\text { EDI groupware }\end{array}$ & $\begin{array}{l}\text { One years from post-adoption } \\
\text { of legacy EDI groupware }\end{array}$ \\
\hline Link to economic performance & Normal & $\begin{array}{l}\text { Indication of improvement } \\
\text { in financial savings }\end{array}$ & $\begin{array}{l}\text { Strong indication of } \\
\text { Improvement in financial savings }\end{array}$ \\
\hline $\begin{array}{l}\text { Technical and organizational } \\
\text { infrastructure }\end{array}$ & Normal & $\begin{array}{l}\text { Increased involvement in both } \\
\text { Intranet and internet technology } \\
\text { and WWW infrastructure }\end{array}$ & $\begin{array}{l}\text { Exponential increased involvement } \\
\text { in both Internet and Intranet } \\
\text { technology and WWW infrastructure }\end{array}$ \\
\hline Flexible knowledge structure & Not appealing & Satisfaction & Increasingly appealing/satisfaction \\
\hline Knowledge-friendly culture & $\begin{array}{l}\text { Negative attitude to knowledge, } \\
\text { organization learning low, } \\
\text { innovation low }\end{array}$ & $\begin{array}{l}\text { Towards positive attitude to } \\
\text { knowledge, organization learning } \\
\text { increase, innovation increasing }\end{array}$ & $\begin{array}{l}\text { Positive attitude to knowledge, } \\
\text { organization learning increase, } \\
\text { innovation increasing }\end{array}$ \\
\hline Clear purpose and language & Not determined & $\begin{array}{l}\text { Objectives being defined in } \\
\text { company mission statement }\end{array}$ & $\begin{array}{l}\text { Objectives being defined } \\
\text { in company mission statement }\end{array}$ \\
\hline Change in motivational practices & No incentives and rewards system & $\begin{array}{l}\text { Staff are motivated by } \\
\text { incentives and rewards system }\end{array}$ & $\begin{array}{l}\text { Staff are motivated by incentives and } \\
\text { rewards system }\end{array}$ \\
\hline $\begin{array}{l}\text { Multiple channels for } \\
\text { knowledge transfer }\end{array}$ & Confined to face to face & $\begin{array}{l}\text { Internet access for } \\
\text { customer request }\end{array}$ & $\begin{array}{l}\text { Face to face, electronic forms of } \\
\text { communication }\end{array}$ \\
\hline Senior management support & Management participation low & $\begin{array}{l}\text { Indications of management } \\
\text { support increases }\end{array}$ & $\begin{array}{l}\text { Indications of management } \\
\text { support increases }\end{array}$ \\
\hline
\end{tabular}

The above indicator (Table 2) provides the finding for the legacy EDI groupware project in trying to achieve. These are as follows:

- In the scope of creating knowledge repositories, it created a virtual 'information library' accessible 24 $\mathrm{h}$ a day to staff across all branches. The significant improvement observed was due to the external knowledge (knowledge from an external source). This means that improved information exchange can lead to intangible benefits, cost reduction and quality improvement efforts

- In the scope of improving knowledge access, it has helped to facilitate the transfer of tacit knowledge between the individuals

- In the scope of enhancing the knowledge environment, it has helped to induce an environment for sharing knowledge

In summary, the legacy EDI groupware project has successfully created a knowledge repository for knowledge transformation, sharing and knowledge creating processes for Organization A. This project entails staff of Organization A's tacit knowledge, which can now be codified into formulated knowledge and now resides on electronic form. In addition, the legacy EDI groupware project has also proven to be successful in allowing information sharing and collaboration across departments and functions (Herdawatie et al., 2009).

Stage two; strategies for KM project (Table 3): How was the groupware project objectives achieved?

To answer the question of how the achievements of the groupware project objectives came about, it is necessary to explore the three major of components of the legacy EDI groupware project. These are as follows: Functionality databases (operational and administration), external network (suppliers and customers) and list servers (end-users). The list server component fits into the personalization strategy because it involves the exchange of ideas and experiences between individuals, i.e., end users. However, the other two components do not fit into either of the strategies, i.e. the codification strategy or the personalization strategy. This means that both the functionality databases and external networks focus on explicit knowledge and are not concerned with codifying knowledge. However, the functionality databases and external network components provide only access to already codified knowledge resides in the electronic form.

Stage three; success indicators for KM project (Table 4): How successful was the groupware legacy EDI project to Organization A? 
The above indicator (Table 4) provides findings on the level of success for the legacy EDI groupware project in Organization A:

- In regards to the scope of growth in resources attached to the project, the estimated total costs of ownership for implementing the project was $\$ 98,400$. However, the estimates of the annual budget of recurring or operational costs would be $\$ 24,000$ per annum

- In regards to the increase in the growth in knowledge content and its usage, there was an exponential increase in information usage since the post adoption of the groupware

- In regards to the extent of organizational initiative, there seems to be greater levels of satisfaction on the part of end user. Customers' complaints have dropped significantly since the adoption of legacy EDI groupware in the organization

- In the regards to the size of the financial return, there seems to have been some reduction in cost, as the legacy EDI groupware is able to integrate web EDI with their inventory, accounting and order entry system. This means that the integration brings about an increase because it greatly decreases human involvement in information flow, thus making business processes simpler, faster, cheaper and less error prone

In summary, the success indicators have indicated that a significant impact to Organization A has occurred. They have improved the quality of their management decision making and thereby improved the quality of service provided to their customers.

Stage four; success factors for KM project (Table 5): Why was the groupware project successful or unsuccessful to Organization A?

For Organization A, the findings of the success factors are as follows:

- Concerning the extent of linking to economic performance, this project has saved significant amounts of money for Organization A. However, the estimated total costs to the owner for implementing the legacy EDI groupware project was $\$ 98,400$. It was anticipated to produce an increase of annual sale of Aus \$30 million (from Aus $\$ 100$ million to Aus $\$ 130$ million) a year after implemented the KM project

- Concerning the scope of technical and organizational infrastructure, this project used
Internet and Intranet technical infrastructure and the World Wide Web

- Concerning the degree of flexible knowledge structure, the project involved different levels of structure of knowledge content. Some have sophisticated indexing structures; that is, information generated from the integration with the internal accounting and inventory system or information transformed through search engines

- In the scope of knowledge friendly culture, there was an indication of positive attitude to knowledge sharing particularly from suppliers and among other staff. For example, supplier coordination, including smooth flows of information provides greater information linkage and able to gain a competitive advantage over their rivals

- In the scope of clear purpose and language, the project has provided staff and suppliers with access to on-line inventory request to support in inventory turnover. It also provided speedy information sharing with customers

- In the scope of motivation to share knowledge, the project has successfully proven that staffs were motivated to share knowledge through an incentives or rewards system

- In the scope of multiple channels for knowledge transfer, the project has provided two channels for knowledge transfer, both electronic: Through the Internet for customers to access to the latest product information and through the list-servers for staff to share knowledge and experiences amongst individuals

- Assessing the extent of senior management support, the project has promoted and secured active participation among management

In summary, the legacy EDI groupware project has satisfied most of the eight success factors defined in the framework. The legacy EDI groupware has also successfully offered cost savings to Organization A, which flow from improved information exchanges between its customers and its suppliers.

\section{DISCUSSION}

Demonstrated in this study, is the proposal that legacy EDI groupware has successfully offered infrastructure to Organization A, which has supported the acquisition of knowledge and enhance the environment in which knowledge artifacts are created and managed. Several reasons are associated with the 
significant of legacy EDI groupware particularly to Organization A:

- The recognition that legacy EDI groupware is the most popular and effective application used by the staffs of Organization A on a daily basis. It is widely noted as being helpful in its virtual office environment as its geographically dispersed branches can collaborate and exchange information

- Legacy EDI groupware is able to provide network tools such as shared, indexed and replicated document databases and discussion threads, as well as shared white broads, joint document editing capabilities and full duplex, multimedia communication features. These tools serve to mitigate collaborative losses

- Substantial cost savings result because of improved information exchanges between Organization A, its suppliers and its customers. These tools serve to add value to Organization $\mathrm{A}$ products and the services to its customers. They also help Organization A to gain a competitive advantage over its rival

- Using legacy EDI groupware to do businesses in the end may enable Organization A to relinquish its control over its suppliers

The choice of legacy EDI groupware project as a mean of supporting knowledge management in providing value creation for Organization A, was because of the consideration given to the premise that this project was able to provide a strategy for managing and exploiting knowledge. This project also serves to help Organization A in understanding its knowledge asset, i.e., the value and utilization of its knowledge, in assessing how well that knowledge is used and the true cost of its IT operations.

\section{CONCLUSION}

The approach used in this study is to address factors affecting the legacy EDI groupware project by using an analysis framework (Moody and Shanks, 1999). It does not propose to build a new model that provides a new way of looking at IT investments that will help to identify its benefits. This refers to a model that is able to address a new focus of responsibility for the identification and delivery of IT investment benefits. However, the factors that have been combined into Moody and Shanks's model that describe and explain the drivers and critical success factors for knowledge management project implementations, requires further testing for thorough empirical validation.

The results of this study also suggest the effective and efficient and empowering conversion of tacit knowledge to explicit knowledge, augmented by a system such as legacy EDI groupware, could enable organisations to manage organisational learning, and also to apply that knowledge to the solution of problems and the fulfilment of new opportunities

The study outlined in this study may encourage other IS scholar to formulate a model that can capture the information reflecting the perception and practice of the Adoption Electronic Commerce Knowledge Management Project. In particular, it would be useful to identify the internal or external environment factors affecting the adoption of them and their degree of influence.

Finally, this study will help other website design consultants to understand why legacy EDI groupware KM projects are successful. The authors have identified the factors that contributed to the success of the project and compared these to success factors identified in the literature.

\section{REFERENCES}

Ahmad, A.R., N.Z. Abiddin, J. Badusah and P.S. Wai, 2009. Computer usage and achievement among adults in rural area Malaysia. J. Soc. Sci., 5: 1-8.

Bernard, R., 1996. The Corporate Intranet. Cichester Wiley and Sons, New York, ISBN: 0471345954.

Ciborra, C.U. and G. Patriotta, 1996. Groupware and Teamwork in New Product Development: The Case of a Consumer Good Multinational, In: Groupware and Teamwork, Invisible Aid or Technical Hindrance? Ciborra, C.U. (Ed.). John Wiley, Chichester, pp: 23-60.

Davenport, T.H., D.R. De Long and M.C. Beers, 1998. Successful knowledge management projects. Sloan Manage. Rev., 39: 43-52.

De Long, D.W. and L. Fahey, 2000. Diagnosing cultural barriers to knowledge management. Acad. Manage. Execut., 14: 113-127.

Hansen, M., H. Nohria and T. Tierney, 1999. What's your strategy for managing knowledge? Harvard Bus. Rev., 77: 106-116.

Hauben, M. and R. Hauben, 1997. Netizens on the History and Impact of Usenet and the Internet. IEEE Computer Society Press, California, pp: 3-9.

Herdawatie, A.K., A.W. Mohd and N.A. Siti, 2009. Boarding school students monitoring systems (EID) using radio frequency identification. J. Soc. Sci., 5: 206-211. 
Moody, D.L. and G.G. Shanks, 1999. Using knowledge management and the internet to support evidence based practice: a medical case study. Proceeding of the 10th Australasian Conference on Information Systems, Dec. 13-16, IEEE., USA., pp: 660-667.

Newman, V., 1997. Redefining knowledge management to deliver competitive advantage. J. Knowl. Manage., 1: 123-128.

Nonaka, I., 2006. Organizational knowledge creation theory: Evolutionary paths and future advances. Org. Stud., 27: 1179-1208.

Nonaka, I. and H. Takeuchi, 1995. The Knowledge Creating Company: How Japanese Company Create the Dynamics of Innovation. Oxford University Press, New York, ISBN: 0-19-5092694, pp: 107-136.

Offsey, S., 1997. Knowledge management: Linking people to knowledge for bottom line results. J. Knowl. Manage., 1: 113-122.

Pan, S.L. and H. Scarbrough, 1999. Knowledge management in practice: An exploratory case study. Technol. Anal. Strat. Manage., 11: 359-374.
Remenyi, D., 1999. The elusive nature of delivering benefits from it investment. http://is.twi.tudelft.nl/ejise/vol14/paper1.html

Remenyi, D., 2004. The elusive nature of delivering benefits from IT investment. Elect. J. Inform. Syst. Evaluat., 3.

The IMPACT Programme, 1998. Working Group 4 of Project Achieve. Exploiting the Wired-Up World: Best Practice in Managing Virtual Organizations. The IMPACT Programme, London.

Wong, E.S., 2003. Action Research Philosophy: The Fountain of Living Research. Perth. Centre of Professional Practitioner Resources Publication, ISBN: 1-74052111-2.

Wong, E.S., 2004. Action research: The living thesis. Centre of Professional Practitioner Resources Publication, Perth, ISBN: 1-74052109-9.

Yin, R.K., 1994. Case Study Research Design and Methods. 2nd Edn., Sage, California, ISBN: 978-14129-6668-9. 